\title{
Evolution of intake capacity of dairy cows in early lactation
}

\author{
P Faverdin, E Leclerc, MC Rousselot, JL Troccon
}

INRA-SRVL, 35590 St-Gilles, France

The prediction of dry matter intake (DMI) of dairy cows in early lactation is still not very accurate. The aim of this work is to study the respective part of precalving characteristics (body reserves, energy intake) and lactation features (energy requirement, concentrate intake) in the evolution of DMI in early lactation.

A weekly database was built using data on 617 early lactations (183 primiparous and 434 multiparous) of Holstein cows calving between 1984 and 1992 at the research station of St-Gilles. The study, only used data for the 12 first weeks of lactation, with maize based diets given ad libitum. DMI multiple regressions were calculated each week to study the evolution of the regression coefficients for pre- and postcalving covariates. Body condition score 2 weeks before calving (BCS . $_{2}$ ) (only 268 lactations) and daily body weight gain during dry period $\left(B W G_{d p}\right.$ ) (351 lactations, no primiparous) were used to describe cow characteristics at calving. Milk production, concentrate intake and body weight were available for all cows to describe the characteristics evolution of lactating cows. Different groups of cows were considered according to the number of lactation $(L 1, L 2$ and $L 3$ respectively for cows in first, second or later lactation) and age at the first calving (A2 before 850 days, $A 3$ after).
The table summarizes the evolution of partial regression coefficients in young (L1A2) and adult cows (L3). Evolution coefficients in second lactation cows show intermediate values. The effects of $B W G_{d p}$ and concentrate intake are very significant in the first week of lactation and decrease later. Both are related to the level of energy intake in late pregnancy. This could indicate that higher energy intake before calving permit higher DMI in early lactation. High values of $\mathrm{BCS}_{-2}$ markedly reduce $D M I$ of primiparous cows, but not adult cows. The BCS $\mathrm{S}_{.2}$ coefficient in L1A2 group increases with the advance of lactation from -1.1 to $-3.8 \mathrm{~kg}$ of $\mathrm{DM} / \mathrm{BCS}_{.2}$ point and is always significant $(n=32)$. The effect of milk production increases with the advance of lactation. The body weight present similar evolution to milk production in adult cows but has not effect in primiparous cows, probably due to high negative effect of $\mathrm{BCS}_{-2}$. After the first month of lactation, coefficient of concentrate intake is in good agreement with the values of the substitution rates reported in the literature.

The variations of DMI can mainly be explained in the first weeks by criteria related to energy intake in late pregnancy $\left(B W G_{d p}\right.$ and concentrate intake) and later by energy requirements (milk production and body weight) except for primiparous cows, where the effect of $\mathrm{BCS}_{-2}$ is very significant.
First calving 2 years old $(L 1 A 2, n=101)$

Partial regression coefficient
Milk yield
Live weight 1st week
Concentrate intake
BWG $_{\mathrm{dp}}$
$\mathrm{RSD}^{1}(\mathrm{~kg} \mathrm{DM} / \mathrm{d})$

\begin{tabular}{|c|c|c|c|}
\hline \multirow[b]{2}{*}{ 1st wk } & \multicolumn{3}{|c|}{$(L 1 A 2, n=101)$} \\
\hline & 5th & 9th & 12th \\
\hline $0.05^{\text {ns }}$ & $0.03^{\text {ns }}$ & $0.09^{\circ}$ & $0.14^{*}$ \\
\hline $0.91^{\circ}$ & $0.51^{\text {ns }}$ & $0.20^{\mathrm{ns}}$ & $0.28^{\mathrm{ns}}$ \\
\hline $1.08^{\prime \prime}$ & $0.44^{*}$ & $0.51^{* *}$ & $0.53^{*}$ \\
\hline \multicolumn{3}{|c|}{ not available } & \\
\hline 1.50 & 1.59 & 1.31 & 1.72 \\
\hline
\end{tabular}

$1 \mathrm{RSD}$ : residual standard deviation.

ns., " : P level of covariate coefficient $>0.05,<0.05$ and $<0.01$ respectively
Third lactation and more

\begin{tabular}{|c|c|c|c|}
\hline \multirow[b]{2}{*}{ 1st } & \multicolumn{2}{|c|}{$(L 3, n=204)$} & \multirow[b]{2}{*}{ 12th } \\
\hline & 5 th & 9th & \\
\hline $0.09^{\circ}$ & $0.15^{* \prime}$ & $0.21 *$ & $0.2 \overline{5^{* \prime}}$ \\
\hline $0.44^{n}$ & $0.33^{\text {ns }}$ & $0.68^{* *}$ & $1.18^{\circ *}$ \\
\hline $1.06^{\prime \prime}$ & $0.54^{*}$ & $0.42^{* *}$ & $0.20^{\circ}$ \\
\hline $1.85^{\circ}$ & $0.73^{\circ}$ & $0.33^{\text {ns }}$ & $0.04 \mathrm{~ns}$ \\
\hline 2.08 & 1.75 & 1.55 & 1.78 \\
\hline
\end{tabular}

